\title{
A Commentary on "Resilience and Water Governance: Adaptive Governance in the Columbia River Basin"
}

Brian H. Walker ${ }^{1}$

As one of the respondents who participated in the "Resilience and Law" panel session at the 2011 Resilience Conference, my intentionally provocative opening comments were to the effect that lawyers and the legal system are amongst the major causes of low and declining resilience in the western world. In short, Cosens and Williams (2012) is an excellent counterpoint to this view - at least as far as the effects of lawyers goes.

Before starting to read the paper I jotted down five insights about resilience in social-ecological systems (SES) that emerge from a range of case studies in the Resilience Alliance (www.resalliance.org). I wanted to see the extent to which they might feature in an account of resilience and governance from a lawyer's perspective. They are:

i) You cannot understand or manage a SES at one scale. SESs are inherently multiscale and their dynamics are dominated by cross-scale interactions.

ii) Trying to make a SES very resilient in one way, at one scale, can lead to it becoming less resilient in other ways at other scales.

iii) Resilience is not about not changing. Trying to keep a SES in one particular state, or protecting it from disturbance in an effort to prevent change, lowers its resilience. (Example: the only way to keep a forest resilient to fire is to burn it every now and then).

iv) Most losses in resilience are unintentional consequences of narrowly focused optimization.

v) Resilience is neither good nor bad. There are many examples of very resilient undesirable system states (dictatorships, salinized landscapes).

Cosens and Williams' paper addresses all of these points to some extent. It does not provide solutions to resolving them all, but it illustrates the awareness of the role of governance and the law in influencing them.

In the limited space I have here, rather than commenting on the many good points the paper makes I want to make two main points of my own, leading to an overall point.

1. A major thrust of the paper is on the need for adaptive management and adaptive governance to be considered together, as necessarily interlinked. It illustrates very well how adaptive management on its own is almost bound to fail. The rules for allowing change in policy/management, in an adaptive way, have to co-evolve with the changing system and the associated requirement for adaptive change in management (and policy). A crucial question that arises when addressing how to achieve this is "What are the rules for changing the rules?" It is crucial because the time scales of the biophysical system responses and the social (legal) system responses can be significantly mismatched, preventing timely changes in management.

If the rules for changing the rules can be agreed on before change is required the mismatch can be reduced. An important part of effecting this is the 'legitimacy' issue raised by Cosens and Williams. Of the three sources of legitimacy for an administrative process that she discusses, the second one (the need for 'order' - clear, stable rules) conflicts with what is needed for adaptive management. It adds to the need for adaptive governance to be included in the third, 'deliberative' source; i.e., including in the public discourse that is necessary for developing legitimacy the need for changes in rules (adaptive governance).

2. Adaptive management is vitally important for achieving resilient systems, but it can only get us so far. When external conditions (like climate change or national/global economics) render continuation of the existing state of the system untenable, the only option is transformation to some other kind of system, not just to an alternate stability domain of the existing system, but into a different kind of system with different defining variables. And this applies at all scales of a system. As an example from my own country, for the MurrayDarling Basin to continue as a resilient agricultural socialecological system supporting high levels of human wellbeing, not all parts of it can continue doing what they are doing now. There is not enough water for all existing agricultural irrigation systems to continue being irrigation systems; some will need to transform into some other kind of agriculture or other human enterprise (i.e., they will no longer have 'water for irrigation' as one of their defining system variables). So the question facing the region becomes: "Where is there a need to build resilience of the existing system, and where is there a need for transformational change?" That question, I suggest, applies all over the world, at all scales up to the globe itself. And it isn't only lower scale transformations in order to secure higher 
scale resilience that is needed. Higher scale transformational change may be necessary for lower scale resilience to be maintained. Preventing declining resilience in many regions of the world (with consequent negative shifts in wellbeing in those regions) will require transformational change in the current global economic system.

The overall point is the clear need for more attention to be paid to understanding, defining, and being able to implement adaptive governance. Without it we will not be able to achieve either adaptive management for resilience, nor necessary transformational change.

Responses to this article can be read online at:

http://www.ecologyandsociety.org/issues/responses. php/5422

\section{LITERATURE CITED}

Cosens, B. A., and M. K. Williams. 2012. Resilience and water governance: adaptive governance in the Columbia River basin. Ecology and Society 17(4): 3. http://dx.doi.org/10.5751/ ES-04986-170403 